\title{
Evidence-Based Supplements for the Enhancement of Athletic Performance
}

\author{
Peter Peeling and Martyn J. Binnie \\ The University of Western Australia and Western Australian Institute of Sport \\ Paul S.R. Goods \\ Western Australian Institute of Sport \\ Marc Sim \\ Edith Cowan University
}

Louise M. Burke

Australian Institute of Sport and Australian Catholic University

\begin{abstract}
A strong foundation in physical conditioning and sport-specific experience, in addition to a bespoke and periodized training and nutrition program, are essential for athlete development. Once these underpinning factors are accounted for, and the athlete reaches a training maturity and competition level where marginal gains determine success, a role may exist for the use of evidence-based performance supplements. However, it is important that any decisions surrounding performance supplements are made in consideration of robust information that suggests the use of a product is safe, legal, and effective. The following review focuses on the current evidence-base for a number of common (and emerging) performance supplements used in sport. The supplements discussed here are separated into three categories based on the level of evidence supporting their use for enhancing sports performance: (1) established (caffeine, creatine, nitrate, beta-alanine, bicarbonate); (2) equivocal (citrate, phosphate, carnitine); and (3) developing. Within each section, the relevant performance type, the potential mechanisms of action, and the most common protocols used in the supplement dosing schedule are summarized.
\end{abstract}

Keywords: athlete performance, ergogenic aids, nutritional intervention

Numerous factors contribute to peak athletic performance. Among these, a strong foundation in physical conditioning and sport-specific experience, in addition to a bespoke and periodized training and nutrition program, the latter based predominately from whole food choices, are essential. Once these underpinning factors are accounted for, and the athlete reaches a training maturity and competition level where marginal gains determine success, a role may exist for the use of evidence-based performance supplements. Although an array of supplements are marketed for the enhancement of sports performance, many lack robust evidence of an ergogenic benefit. Furthermore, some may actually impair performance, often due to gastrointestinal (GI) concerns, while others are potentially detrimental to an athlete's health. Finally, numerous ingredients in commercial supplements, sometimes presenting as contaminants or undeclared ingredients, carry a risk of inadvertent

Peeling and Binnie are with the School of Human Sciences (Exercise and Sport Science), The University of Western Australia, Crawley, Western Australia, Australia. Peeling, Binnie, and Goods are with the Western Australian Institute of Sport, Mount Claremont, Western Australia, Australia. Sim is with the School of Medical and Health Sciences, Edith Cowan University, Joondalup, Western Australia, Australia. Burke is with the Australian Institute of Sport, Bruce, Australia; and with the Mary MacKillop Institute for Health Research, Australian Catholic University, Melbourne, Australia. Address author correspondence to Peter Peeling at peter.peeling@uwa.edu.au. anti-doping rule violations (Baylis et al., 2001). With this in mind, athletes and their associated support teams should only consider performance supplements where a strong body of evidence supports their use as safe, legal, and effective.

The following review focuses on the available evidence base for performance supplements that are commonly used in sport, summarizing the type of event/exercise scenario they are suited to, the potential mechanisms of beneficial effects, and the typical dosing schedule/protocols of use. The supplements of interest have been divided into three categories according to the strength of evidence supporting their use for the enhancement of sports performance. These categories include: (1) established, (2) equivocal, and (3) developing performance supplements.

\section{Established Performance Supplements}

There is robust evidence that the following supplements can enhance sports performance when used according to established protocols.

\section{Caffeine}

Caffeine, a stimulant that is ubiquitously consumed in the diets of most adults, has well-established benefits for athletic performance. 
The mechanisms underpinning these benefits include adenosine receptor antagonism, increased endorphin release, enhanced neuromuscular function, improved vigilance and alertness, and a reduced perception of exertion during exercise (for review, see Burke, 2008; Goldstein et al., 2010; Spriet, 2014). There exists a lengthy research history on caffeine supplementation across a range of performance protocols, including endurance-based situations, resistance training exercise, short-term supramaximal efforts, and/ or repeat-sprint tasks. Of note, recent interest in this area includes investigation into the efficacy of lower caffeine doses, variations in the timing of intake before and/or during exercise, and the lack of need to include a withdrawal period for performance effect optimization (Burke, 2008).

Endurance performance. Caffeine supplementation is known to improve endurance capacity during time to fatigue exercise tasksfor instance, during activities such as treadmill running to exhaustion (French et al., 1991) and resistance training exercise repetitions to failure (Duncan et al., 2013). Furthermore, ergogenic benefits are also widely reported during competitive situations, such as real or laboratory-simulated time-trial (TT) activities. A systematic review by Ganio et al. (2009) of 33 trials (representing 21 studies) found that caffeine supplementation achieved an average performance benefit of $\sim 3.2 \%( \pm 4.3 \%)$ when provided before and/or during endurance-based TT activities of varying duration (5-150 $\mathrm{min})$, across numerous exercise modalities (i.e., cycling, running, rowing, cross-country skiing, and swimming). Studies reporting benefits typically used caffeine dosages of $3-6 \mathrm{mg} / \mathrm{kg}$ of body mass $(\mathrm{BM})$, in the form of anhydrous caffeine (i.e., pill or powder form), consumed $\sim 60$ min prior to exercise (Ganio et al., 2009). However, there is also a growing body of work investigating the use of lower caffeine doses ( $<3 \mathrm{mg} / \mathrm{kg} \mathrm{BM}, \sim 200 \mathrm{mg}$ ), provided both before and during exercise, which also reports an ergogenic benefit (Spriet, 2014). Of note, larger caffeine doses ( $\geq 9 \mathrm{mg} / \mathrm{kg} \mathrm{BM})$ do not appear to increase the benefit to performance (Bruce et al., 2000). In fact, such doses are likely to increase the risk of negative side effects, such as nausea, anxiousness, insomnia, and restlessness (Burke, 2008)_outcomes that would clearly negate any performanceenhancing outcomes. Interestingly, similar performance outcomes are expected in both habituated caffeine users and nonusers (Goldstein et al., 2010), with recent research reporting that high habitual daily caffeine intake (defined as $351 \pm 139 \mathrm{mg} /$ day) was associated with equivalent absolute and relative performance benefits as seen in low and moderate daily caffeine consumers (Gonçalves et al., 2017).

Low doses of caffeine consumed during endurance exercise have also been shown to enhance performance. In fact, 100-200 mg $(1.5-2.9 \mathrm{mg} / \mathrm{kg} \mathrm{BM})$ of caffeine consumed in combination with a carbohydrate electrolyte solution after $80 \mathrm{~min}$ of a preload cycling task was shown to result in a $\sim 4-7 \%$ improvement during a subsequent TT completed in $26-28$ min (Talanian \& Spriet, 2016). Furthermore, 200-300 mg of caffeine administered in chewing gum form at the $10-\mathrm{km}$ point of a $30-\mathrm{km}$ cycling TT was shown to improve mean power output $(+3.8 \%)$ during the final $10 \mathrm{~km}$ of the task, in addition to a $4 \%$ increase in peak sprint power output at the end of the task (Paton et al., 2015). In summary, caffeine supplementation provided both before and/or during endurance-based TT activities is likely to achieve positive performance outcomes.

Short-term, supramaximal, and repeated sprint tasks. The effects of caffeine on short-term, supramaximal, and repeated sprint tasks have been less well studied. Nevertheless, a systematic review of caffeine ingestion and high-intensity efforts of $\leq 5 \mathrm{~min}$ duration reported that $\sim 65 \%$ of studies resulted in performance benefits, with a mean task improvement of $\sim 6.5 \% \quad( \pm 5.5 \%$; Astorino \& Roberson, 2010). Specific protocols involving anaerobic activities include the study of a 1-km cycling TT, where caffeine ingestion $(5 \mathrm{mg} / \mathrm{kg}$ BM consumed $60 \mathrm{~min}$ preexercise) was associated with a $3.1 \%$ improvement in task completion time, and a $3.1 \%$ and $8.1 \%$ improvement in mean and peak power output, respectively (Wiles et al., 2006). Such performance benefits have also been realized during short-duration maximal dynamic resistance training exercise, where measures of muscle torque production were significantly improved after the consumption of $6 \mathrm{mg} / \mathrm{kg}$ caffeine in the $60 \mathrm{~min}$ prior to exercise (Duncan et al., 2014). Furthermore, low caffeine doses administered in chewing-gum form (100 $\mathrm{mg}$ chewed for $5 \mathrm{~min}$ immediately preexercise) were shown to increase the distance thrown $(+6 \%)$ by well-trained collegiate shot putters (Bellar et al., 2012). With respect to simulations of team sport activity, caffeine ingestion $(6 \mathrm{mg} / \mathrm{kg} \mathrm{BM}$, $50 \mathrm{~min}$ before warm-up) improved total work performed during the first $(+8.5 \%)$ and second half $(+7.6 \%)$ of a $2 \times 36$ min repeatsprint protocol in moderately-trained team sport athletes (Schneiker et al., 2006). Furthermore, a 1\% improvement in mean sprint time was shown, when $300 \mathrm{mg}$ caffeine was provided 60 min prior to a rugby-specific repeated sprint test in semiprofessional rugby-league players (Wellington et al., 2017).

In summary, low to moderate doses of caffeine $(\sim 3-6 \mathrm{mg} / \mathrm{kg}$ $\mathrm{BM})$, consumed $60 \mathrm{~min}$ preexercise, appear to have the most consistent positive outcomes on sports performance in research situations, although a variety of other protocols (as mentioned above) also appear beneficial, and are practiced in real-life. Of note, athletes who intend to use caffeine as a performance aid should trial their strategies during training or minor competitions, in order to fine-tune a protocol that achieves benefits with minimal side effects.

\section{Creatine}

Creatine is another widely-researched supplement, with creatine monohydrate $(\mathrm{CM})$ being the most common form used to supplement dietary intake from meats. When taken according to established loading and/or maintenance protocols, creatine supplementation can increase intramuscular creatine stores by $\sim 30 \%$ (Harris et al., 1992), with the magnitude of response being inversely related to the starting concentration (Volek \& Rawson, 2004). Within the muscle, creatine-kinase mediates the phosphorylation of creatine to phosphocreatine (PCr), a key substrate for highintensity muscle force generation (Greenhaff et al., 1993). Whereas PCr levels decrease during high-intensity exercise to rapidly resynthesize adenosine triphosphate (ATP) from adenosine diphosphate (ADP; Rawson \& Persky, 2007), elevated creatine stores allow a greater rate of $\mathrm{PCr}$ resynthesis, enhancing short-term, high-intensity exercise (Buford et al., 2007), particularly by enhancing the capacity to perform repeated bouts of effort.

Numerous reviews of CM supplementation identify performance benefits in single $(+1-5 \%)$ and repeated bouts $(+5-15 \%)$ of high-intensity exercise of $<150 \mathrm{~s}$ in duration, with the most pronounced effects being seen during tasks of $<30$ s (Branch, 2003; Lanhers et al., 2017). As a result, creatine loading can acutely enhance the performance of sports involving repeated highintensity exercise (e.g., team sports), as well as the chronic outcomes of training programs based on these characteristics (e.g., resistance or interval training), leading to greater gains in lean mass and muscular strength and power (Rawson \& Persky, 2007; 
Volek \& Rawson, 2004). There is additional, albeit equivocal, evidence of changes in cellular signaling, metabolism, and water storage associated with creatine supplementation with potential flow-on effects such as enhancements of protein synthesis, glycogen storage, and thermoregulation (for review, see Cooper et al., 2012; Kreider et al., 2017). Therefore, there may be less wellrecognized benefits of creatine supplementation for endurance sport athletes. In fact, recent evidence has shown that a combination of creatine (20 g/day for 5 days $+3 \mathrm{~g} /$ day for 9 days) and carbohydrate ( $\mathrm{CHO}, 6-12 \mathrm{~g} / \mathrm{kg} /$ day) loading may result in an increased power output during repeated high-intensity sprint efforts undertaken during the late stages of prolonged $(>3 \mathrm{hr}$ ) simulated TT cycling, possibly reflecting the physiological demands of a latestage breakaway during endurance events (Tomcik et al., 2018). However, CM supplementation is frequently reported to result in a 1-2 kg increase to body mass after the "loading-phase", likely a result of water retention (Buford et al., 2007), which may, in fact, be counteractive for the performance of endurance and/or other weight-sensitive sports, and should therefore be considered when choosing to use this supplement.

A recent meta-analysis of the most common and effective strategies for CM supplementation determined that a "loadingphase" of $20.9 \pm 4.5 \mathrm{~g} /$ day (divided into four equal 5 -g doses per day), for 5-7 days was reported across $>80 \%$ of CM studies (Lanhers et al., 2017). Subsequently, a "maintenance-phase", typically involving a single 3-5-g CM dose per day, should follow the "loading phase" for the duration of the supplementation period. Such protocols have been established primarily from early work investigating muscle creatine loading in males (Hultman et al., 1996). Interestingly, concurrent consumption of CM with a mixed protein/carbohydrate source ( $\sim 50 \mathrm{~g}$ of protein and carbohydrate) appears to enhance muscle creatine uptake via an insulin-mediated effect (Steenge et al., 2000), suggesting that creatine doses are best taken with a meal (or separate food supplement). No negative health effects have been reported with the long-term use of CM (up to 4 years) when appropriate loading protocols are followed (Schilling et al., 2001). In fact, some reports propose CM supplementation to be anti-inflammatory, and to reduce exercise-induced oxidative stress (Deminice et al., 2013). In summary, when accepted CM supplementation protocols are followed, the expected increase in intramuscular creatine stores are likely to enhance lean mass, maximal power/strength, and the performance of single and repeated bouts of short-term, high-intensity exercise.

\section{Nitrate}

Dietary nitrate $\left(\mathrm{NO}_{3}{ }^{-}\right)$is a popular supplement initially found to improve oxygen uptake $\left(\mathrm{VO}_{2}\right)$ kinetics during prolonged submaximal exercise (Bailey et al., 2009). The ingestion of dietary $\mathrm{NO}_{3}{ }^{-}$leads to an enhanced nitric oxide (NO) bioavailability via the $\mathrm{NO}_{3}{ }^{-}$-nitrite-NO pathway, a reduction catalyzed initially by bacteria in the mouth and the digestive system (Duncan et al., 1995). NO plays an important role in the modulation of skeletal muscle function (Jones, 2014), with proposed mechanisms for improved exercise performance including a reduced ATP cost of muscle force production, an increased efficiency of mitochondrial respiration, increased blood flow to the muscle, and a decrease in blood flow to $\mathrm{VO}_{2}$ heterogeneities (Bailey et al., 2010).

Of note, $\mathrm{a} \sim 5 \%$ reduction in $\mathrm{O}_{2}$ cost of submaximal exercise following nitrate supplementation, coupled with augmented muscle function, has been associated with large (4-25\%) improvements in time to exhaustion (Jones, 2014), with smaller enhancements observed (1-3\%) in sport-specific, TT performances (McMahon et al., 2016). To date, there is limited support for beneficial effects during exercise $>40 \mathrm{~min}$ in duration, however, this is possibly due to the lower relative exercise intensity, and the diminished role of nitrite-driven pathways for NO production (Jones, 2014). Recently, nitrate supplementation has been proposed to enhance the function of type II muscle fibers (Bailey et al., 2015), with improved performance $(-3-5 \%)$ shown during bouts of high-intensity, intermittent, team-sport exercise of 12-40 min in duration (Thompson et al., 2015; Wylie et al., 2016). However, the evidence remains equivocal for any benefit to exercise tasks of shorter duration ( $<12 \mathrm{~min}$ ), with some studies showing no effect of acute supplementation on repeated sprint performance (Reynolds et al., 2016), and others showing significant benefits in single- $(1.2 \%)$ and repeated-sprint $(3.9 \%)$ tasks following chronic supplementation for 5 days (Thompson et al., 2016). Differences in these findings may possibly relate to the lower dose of nitrate provided in the acute instance; indeed, a dose-response effect of $\mathrm{NO}_{3}{ }^{-}$supplement use has been shown previously, with higher $\mathrm{NO}_{3}{ }^{-}$doses having a greater impact on 2,000-m rowing performance (Hoon et al., 2014). The athlete's training status may also affect the supplement efficacy, with greater amounts of nitrate likely needed to produce an effect in higher-level athletes (Jones, 2014). However, the benefit of nitrate supplementation for very highly-trained (elite) athletes requires more research, with some (Nyakayiru et al., 2017; Peeling et al., 2015), but not all (Boorsma et al., 2014), studies showing benefits in such cohorts. Finally, chronic $\mathrm{NO}_{3}{ }^{-}$supplementation may facilitate training adaptations when taken prior to key sessions, with greater improvements $(8.7 \%$ vs. $4.7 \%$ in placebo control) seen in maximum work rate following 3 weeks of sprint interval training after ingesting $8 \mathrm{mmol}$ (or $500 \mathrm{mg}$ ) of $\mathrm{NO}_{3}{ }^{-} 2.5 \mathrm{hr}$ before each training session (Muggeridge et al., 2017).

Leafy green and root vegetables (i.e., spinach, rocket, celery, beetroot, etc.) are the primary source of dietary $\mathrm{NO}_{3}{ }^{-}$(Jones, 2014); however, a recent meta-analysis of 76 nitrate trials showed that beetroot juice was the supplemental $\mathrm{NO}_{3}{ }^{-}$source used in the majority (76\%) of exercise interventions (McMahon et al., 2016). Performance benefits may manifest acutely (i.e., within 2-3 hr) following a $\mathrm{NO}_{3}{ }^{-}$bolus of 5-9 mmol (310-560 mg) (i.e., Hoon et al., 2014; Peeling et al., 2015), with recent work highlighting that a cumulative influence of repeated $\mathrm{NO}_{3}{ }^{-}$intake ( $>3$ days) may also be beneficial (Thompson et al., 2016; Thompson et al., 2015), especially in well-trained athletes (Jones, 2014). Finally, performance benefits may be maintained for at least 15 days, if consumption of the supplement is continued for this duration (Vanhatalo et al., 2010).

\section{Beta-Alanine}

Beta-alanine is the rate-limiting precursor to carnosine, an endogenous intracellular (muscle) buffer, and one of the immediate defenses against the accumulation of protons in the contracting musculature during exercise (Lancha Junior et al., 2015). Daily supplementation with $3.2-6.4 \mathrm{~g}(\sim 65 \mathrm{mg} / \mathrm{kg} \mathrm{BM})$ of beta-alanine, for a minimum of 2-4 weeks can increase skeletal muscle carnosine content ( $\sim 65 \%$ above resting levels), improving tolerance for maximal exercise bouts lasting $30 \mathrm{~s}$ to $10 \mathrm{~min}$ (Saunders et al., 2016). Small yet significant benefits $(-2-3 \%)$ of beta-alanine supplementation have been shown in both continuous and intermittent exercise tests; however, sport-specific investigations which highlight the practical implications for intermittent sports are distinctly lacking (Hobson et al., 2012; Saunders et al., 2016). Muscle 
carnosine content can be further elevated when supplementation regimes are extended to $10-12$ weeks ( $~ 80 \%$ above resting levels), however, the correlation between muscle changes and magnitude of performance benefit remains unestablished (Saunders et al., 2016). Beta-alanine supplementation may not be as effective in well-trained athletes as their lesser-trained counterparts (Bellinger, 2014), partly due to a diminishing role of carnosine toward intramuscular $\mathrm{pH}$ regulation in individuals with an already enhanced buffering capacity. However, the small performance changes observed in well-trained athletes to date $(0.2-1.3 \%$; Baguet et al., 2010; Chung et al., 2012) may still be meaningful in the context of an applied competition setting.

Beta-alanine dosing strategies typically involve split doses consumed over the day (i.e., $0.8-1.6 \mathrm{~g}$ every $3-4 \mathrm{hr}$ ), and/or slow release formulations to minimize the likelihood of side effects (Saunders et al., 2016), which may range from itchiness and skin rashes through to episodes of transient paresthesia (Stellingwerff et al., 2012). However, large interindividual variations in muscle carnosine synthesis have been reported following beta-alanine supplementation, postulated to have an inverse association with (a) the individual's preingestion levels of carnosine, (b) the individual's training status, and (c) the proportion of fast-twitch muscle fibers (Nassis et al., 2016). However, in accounting for this individual variation, an in-depth analysis and summary of the available literature by Stellingwerff et al. (2012) proposes that, in order to achieve an approximate $50 \%$ increase in muscle carnosine, a total of $\sim 230 \mathrm{~g}$ of beta-alanine should be consumed, encompassing a daily consumption range of 1.6-6.4 g/day. Regardless, it is likely that an individualized approach to beta-alanine supplementation should be considered where possible.

In summary, beta-alanine supplementation via the split dose ingestion of $\sim 3.2-6.4 \mathrm{~g}(\sim 65 \mathrm{mg} / \mathrm{kg} \mathrm{BM})$ per day, consumed for a minimum of 2-4 weeks, and up to 12 weeks, should occur in order to augment high-intensity exercise performance ranging from $30 \mathrm{~s}$ to $10 \mathrm{~min}$ in duration.

\section{Sodium Bicarbonate}

Ingestion of sodium bicarbonate $\left(\mathrm{NaHCO}_{3}\right)$ is proposed to enhance high-intensity exercise performance as an extracellular (blood) buffer; however, the mechanisms of action are complex (Siegler et al., 2016). Although playing an important role in the maintenance of both intracellular and extracellular $\mathrm{pH}, \mathrm{NaHCO}_{3}$ is unable to permeate the sarcolemma, and therefore aids intracellular $\mathrm{pH}$ regulation indirectly by raising both extracellular $\mathrm{pH}$ and $\mathrm{HCO}_{3}{ }^{-}$ concentrations (Katz et al., 1984; Lancha Junior et al., 2015). This effectively increases the $\mathrm{pH}$ gradient between the intracellular and extracellular environments, leading to an enhanced efflux of $\mathrm{H}^{+}$and $\mathrm{La}^{-}$from the exercising muscle during high-intensity activity (Katz et al., 1984; Mainwood \& Worsley-Brown, 1975).

While $\mathrm{NaHCO}_{3}$ ingestion is associated with a high level of intraindividual variability in performance outcomes, benefits are generally seen in short-term, high-intensity sprints lasting $\sim 60 \mathrm{~s}$ in duration (mean performance enhancement of $\sim 2 \%$ ), with a diminishing return as the effort duration exceeds $\sim 10 \mathrm{~min}$ (Carr, Hopkins, \& Gore, 2011); however, greater benefits may be realized ( $>8 \%$ improvement) with a greater number of repeated sprint bouts (Lancha Junior et al., 2015). Successful supplementation protocols typically involve acute $\mathrm{NaHCO}_{3}$ doses of $0.2-0.4 \mathrm{~g} / \mathrm{kg} \mathrm{BM}$, with time to peak $\mathrm{HCO}_{3}{ }^{-}$concentration occurring 60-150 min postingestion (Carr, Hopkins, \& Gore, 2011; Siegler et al., 2012). However, common side effects include GI upset, which may negate any performance enhancements, likely explaining the large variability in individual responses (Carr, Slater, et al., 2011). Strategies to minimize GI upset include co-ingesting $\mathrm{NaHCO}_{3}$ with a small, carbohydrate-rich meal ( $1.5 \mathrm{~g} / \mathrm{kg} \mathrm{BM}$ carbohydrates) (Carr, Slater, et al., 2011); splitting an acute dose into several smaller doses taken over the course of 30-60 min (Krustrup et al., 2015); or "serially" loading with 3-4 smaller doses per day for 2-4 consecutive days prior to an event (Burke, 2013). Furthermore, sodium citrate has been proposed as an alternative to $\mathrm{NaHCO}_{3}$, as a result of lower reported rates (albeit not in all investigations) of GI upset (Requena et al., 2005).

\section{Summary Point for Established Performance Supplements}

It should be considered that each of the supplements listed above may be found in foods considered to be a part of the "everyday diet". Potentially, the aforementioned supplement doses and performance effects are achievable from slightly-elevated dietary consumption of commonly-consumed foods and beverages (i.e., caffeine through coffee intake, and nitrate through leafy green and root vegetable consumption); however, in other cases (i.e., creatine, beta-alanine, and sodium bicarbonate), it may be hard to obtain the required volume without a dedicated supplement source. Regardless, it is no doubt reassuring that each of these established performance supplements can be found in various forms on the shelves and in the fridges of the local supermarket.

\section{Equivocal Performance Supplements}

The following supplements are also used by athletes; however, the evidence-base for their potential to enhance athletic performance is less clear.

\section{Sodium Citrate}

Similar to $\mathrm{NaHCO}_{3}$, sodium citrate acts as a blood buffer by increasing $\mathrm{pH}$ in the extracellular environment, and increasing the gradient between the blood and the active muscle. This is achieved by the dissociation of sodium citrate into its constituent ions, leading to a decrease in $\left[\mathrm{H}^{+}\right]$and an increase in $\left[\mathrm{HCO}_{3}^{-}\right]$as electrical equilibrium is restored (Requena et al., 2005).

Early studies trialed sodium citrate doses ranging from 0.1 to $0.5 \mathrm{~g} / \mathrm{kg} \mathrm{BM}$, consumed 90 min prior to a 60 -s maximal sprint test. Here, a dose response was seen, with ergogenic benefits requiring a minimum ingestion of $0.3 \mathrm{~g} / \mathrm{kg} \mathrm{BM}$, which increased proportionally with the amount of supplement consumed (McNaughton, 1990). Subsequently, a $0.5 \mathrm{~g} / \mathrm{kg}$ BM dose was reported to achieve a $\sim 12 \%$ increase in total work completed over exercise tasks lasting 2-4 min (McNaughton \& Cedaro, 1992), but higher doses $(0.7-0.9 \mathrm{~g} / \mathrm{kg} \mathrm{BM})$ were found to increase the symptoms of GI distress without increasing the degree of alkalosis produced (Urwin et al., 2016). The more recent discovery that the time to peak blood pH occurs 180-240 min after sodium citrate ingestion suggests that the dosing protocol should occur at a minimum of $3 \mathrm{hr}$ preexercise (Urwin et al., 2016).

Despite these few positive investigations, it should be noted that the ergogenic effect of sodium citrate ingestion remains equivocal, with a previous meta-analysis highlighting a negligible benefit $(0.0 \pm 1.3 \%$ improvement $)$ associated with the use of this supplement (Carr, Hopkins, \& Gore, 2011). Considering the detrimental side effects from both $\mathrm{NaHCO}_{3}$ and citrate, and the 
potential for limited benefits with the latter, athletes and support staff are encouraged to carefully trial the use of these blood buffers in training before implementing an individualized and bespoke protocol in a competition setting.

\section{Phosphates}

Numerous hypotheses have been proposed to support the potential benefits of phosphate supplementation on athletic performance (see Buck et al., 2013). The proposed mechanisms underpinning these benefits include an enhanced rate of ATP and PCr resynthesis (Kreider, 1999); improved buffering capacity to support high rates of anaerobic glycolysis (Kreider, 1999); improvement of myocardial contractility leading to increased cardiac efficiency (Kreider et al., 1992); and an increased erythrocyte 2,3 diphosphoglycerate (2,3 DPG) concentration, leading to a reduced affinity of oxygen with hemoglobin and a greater unloading of oxygen to the peripheral tissues (Benesch \& Benesch, 1969).

Current investigations of phosphate supplementation (sodium, calcium, or potassium phosphate) have focused on the physiological and performance-related outcomes of laboratory protocols including graded exercise tests to exhaustion, the 30-s Wingate test, $6 \times 20 \mathrm{~m}(\sim 3-4 \mathrm{~s})$ repeat sprint efforts, and TT situations ranging in duration from 3-60 min. Overall, there is equivocal evidence of performance enhancement from phosphate supplementation. In some instances, phosphate has been shown to enhance $\mathrm{VO}_{2 \max }$ (Cade et al., 1984; Kreider et al., 1990), anaerobic threshold (Kreider et al., 1990), and cycling TT performance (Folland et al., 2008). However, in the case of repeated sprints, the magnitude of benefit has been shown to be varied and unclear (Kopec et al, 2016). Finally, there is also a large amount of contrary evidence from the same physiological and performance measures that suggests phosphate supplementation (in isolation, or in combination with other buffer agents) has no impact on exercise capacity or performance outcomes (Brewer et al., 2014; Goss et al., 2001; Kraemer et al., 1995; West et al., 2012). No doubt, the lack of clear consensus defined by this collective work is explained by variations in the supplement protocol used (i.e., differences in dose, type, exercise protocol, etc.) as well as individual responses to the supplement itself (Peeling, 2015).

Typically, phosphate supplementation is achieved over a 3-6 day period, with a total daily dose of $\sim 50 \mathrm{mg} / \mathrm{kg}$ of fat-free mass $(\sim 3-4 \mathrm{~g})$ consumed in single or split doses throughout the day. This is often associated with GI distress (Cade et al., 1984; West et al., 2012); however, tolerance is improved by concurrent consumption with $\sim 300 \mathrm{ml}$ of a carbohydrate-rich fluid (Brewer et al., 2013). Nevertheless, current evidence regarding the efficacy of phosphate supplementation remains unclear, since there exists no evidence to suggest an accumulation of this supplement in the muscle, where a number of the reported mechanism are suggested to take effect. As such, the use of this supplement for enhanced athletic performance is likely questionable, with further research needed to fully explore its true effect. If considered for use, individual responses should be thoroughly trialed prior to using this supplement in a competition setting.

\section{Carnitine}

Carnitine is a compound predominantly found (95\%) within the skeletal muscle, playing several important roles in substrate utilization. Carnitine assists in the translocation of long-chain fatty acids into the mitochondria for beta-oxidation, as well as providing a sink for excess production of acetyl-CoA, thus assisting the flux of carbohydrate through the citric acid cycle (see Stephens, Constantin-Teodosiu, \& Greenhaff, 2007). Increased muscle carnitine stores via supplementation with L-carnitine are postulated to spare glycogen, via increased fat oxidation, at lower exercise intensities, and to promote more efficient carbohydrate oxidation and reduced lactate accumulation at higher intensities, delaying the onset of fatigue during endurance-based activity.

Research on L-carnitine supplementation has shown equivocal outcomes. Marconi et al. (1985) reported a $6 \%$ increase in $\mathrm{VO}_{2 \max }$ during graded treadmill running, but no change in steady-state $\mathrm{VO}_{2}$ or fuel utilization during submaximal $\left(65 \% \mathrm{VO}_{2 \max }\right)$ exercise when $1 \mathrm{~g}$ of L-carnitine was consumed every $6 \mathrm{hr}$ for 2 weeks. Additionally, Greig and colleagues (1987) found no effects on either $\mathrm{VO}_{2 \max }$ or substrate metabolism with L-carnitine supplementation provided as $2 \mathrm{~g}$ /day in split doses for 2-4 weeks. Of note, the lack of performance effect seen in these studies may likely result from the fact that muscle carnitine levels do not seem to increase when using these standard supplement protocols (i.e., up to $4 \mathrm{~g}$ /day for 14 days; Barnett et al., 1994). More recently, Novakova et al. (2016) suggested that 12 weeks of L-carnitine supplementation ( $2 \mathrm{~g} /$ day in split doses) was associated with a $\sim 20 \%$ increase in the plasma carnitine levels of habitual meat eaters, and a $\sim 30 \%$ increase in vegetarians. However, this failed to change muscle carnitine levels in the meat-eating group, and only translated to a $13 \%$ increase in the vegetarians (who had started the trial with $\sim 10 \%$ lower muscle carnitine levels). Importantly, there was no effect on muscle function, energy metabolism, or $\mathrm{VO}_{2}$ during either submaximal or maximal exercise tests.

It is likely that the lack of efficacy of oral L-carnitine supplementation in many studies is due to its low bioavailability and failure to increase muscle carnitine stores. However, Stephens, Evans, et al. (2007) have shown that whole body carnitine retention can be increased when the supplement is co-ingested with a substantial carbohydrate source to take advantage of an insulinmediated uptake (i.e., 3 g/day consumed with $94 \mathrm{~g} \mathrm{CHO}$ ), over long periods (i.e., 100 days to increase muscle carnitine by $\sim 10 \%$ ). In a follow-up study (Wall et al., 2011), chronic supplementation (twice daily intake of $2 \mathrm{~g}$ L-carnitine plus $80 \mathrm{~g}$ of carbohydrate, for 24 weeks) increased muscle carnitine by $21 \%$, resulting in a $55 \%$ reduction in muscle glycogen utilization during submaximal cycling (30 min@ @50\% $\mathrm{VO}_{2 \max }$ ), better matching of metabolic flux during high-intensity cycling (30 min @ 80\% $\mathrm{VO}_{2 \max }$ ), and an increased work output $(+11 \%)$ during a 30 -min "open-intensity" performance trial (attributed to a reduced anaerobic ATP production). Regardless of these performance benefits, it is likely that these aforementioned ingestion protocols are impractical on a daily basis, and it is also unclear as to the impact that such a dosage regime may have on the individual's health. Therefore, given the limited research in this space, and the considerable effort needed to implement such a protocol, further investigation is needed to clarify the efficacy and safety of following these prolonged supplement regimes.

\section{Developing Performance Supplements}

This section covers supplements which are emerging in both their popularity and the evidence base for athletic performance benefits. However, more work is needed before conclusive recommendations can be made on their use, and there may be some differences in the principles or mechanisms by which they could be of value. The performance supplements outlined in the prior sections are 
presented in view of a strong evidence base to reflect a direct impact on athletic performance through the augmentation of various rate-limiting processes. However, other supplements may have an indirect impact on performance via their ability to support the training process, through their influence on factors such as inflammatory modulation, oxidative stress, and signaling pathways for adaptation, or their ability to support repetitive performance by restoring homeostasis between two exercise bouts. For example, the amino acid $\mathrm{N}$-acetylcysteine acts as an anti-oxidant that may assist in athlete recovery through mediation with exercise-induced reactive oxygen species (see Braakhuis \& Hopkins, 2015). Such an outcome may impact athlete performance-for instance, if the supplement protocol targets an improvement in fatigue resistance during heavy competition schedules. Similarly, food polyphenols may act in a comparable way, possessing strong anti-oxidant and anti-inflammatory properties (see Tsao, 2010) that may be beneficial to exercise recovery. For instance, the high anthocyanin content of tart Montmorency cherries has been shown to reduce the inflammatory and oxidative stress responses to marathon running (Howatson et al., 2010) and during consecutive days of stochastic, high-intensity cycling (Bell et al., 2014). Of note, only blood biomarkers were presented in these aforementioned studies to suggest such a benefit and, therefore, these outcomes should be further confirmed by muscle analysis in future research.

Of note, there are several issues that make it more difficult to substantiate the performance benefits of these supplements. One factor is that it may take a lengthy period before better recovery between exercise bouts or better support of training leads to a detectable improvement in competition performance. Second, there is the possibility that better preservation/restoration of homeostasis, or dampening of the inflammatory and oxidative stress incurred during training sessions, might reduce the adaptation to the exercise stimulus. For example, previous research on supplementation with anti-oxidant vitamins (i.e., vitamins $\mathrm{C}$ and $\mathrm{E}$ ) has shown a reduction in the cellular signaling pathways which underpin the adaptive response to exercise, decreasing the overall training response and reducing any potential improvements to performance (Gomez-Cabrera et al., 2008). As such, the ultimate benefit of the use of these supplements may depend on how and when they are used; for example, they might be used in scenarios of repeated competition events to reduce exercise perturbations and enhance recovery and subsequent performance, but avoided during training bouts where optimal adaptation is driven by full exposure to oxidative or inflammatory stress.

Alternatively, some supplements may affect a number of body systems, with positive effects on one system counteracting the minor negative effects on another. For example, although they are considered to have anti-oxidant properties, some polyphenol subclasses (e.g., the flavonoids) are postulated to enhance the exercise-induced signaling pathways that stimulate mitochondrial biogenesis and changes in vascular function (see Somerville et al., 2017). Furthermore, numerous food polyphenols are also suggested to have a direct effect on performance, potentially a result of mechanisms relevant to flow mediated dilatation, NO production, and adenosine receptor antagonism effects (Somerville et al., 2017). For instance, a daily dose of New Zealand blackcurrant extract (300 mg containing $105 \mathrm{mg}$ of anthocyanins) for a period of 7 days has been suggested to enhance endurance performance by $2-3 \%$ during running $(5 \mathrm{~km})$ and cycling-based $(16.1 \mathrm{~km}) \mathrm{TT}$ activities (Cook et al., 2015; Perkins et al., 2015); and a 500$1,000 \mathrm{mg}$ daily dose of quercetin (consumed over extended periods ranging from 1-8 weeks) has shown clear moderate improvements
$(+2.8 \%)$ to performance when mediating the type of athletic event undertaken (Somerville et al., 2017). However, clearly in its infancy, there exists a need for further research exploring these emerging supplements to fully examine the effects and potential efficacy of their ability to support the training process, and to provide a direct positive impact on athletic performance.

\section{Concluding Remarks}

This review summarizes the evidence for a number of commonlyused supplements, ingested with the aim of enhancing athletic performance. The focus here was on products which have a clear mechanism/function that may be relevant to a given type of sporting activity, as well as a body of research that has investigated the translation of this mechanism into a detectable performance improvement. This type of information allows the coach, athlete, and/or support team to make informed choices about performance supplements that may be relevant to their situation. This should be further viewed in light of the marginal, but often important, gains that may be achieved through sound use of these products, as well as practical considerations such as a lack of uniform tolerance and response to a given supplement. As such, any use of performance supplements should be thoroughly trialed in training before implementation into a competition environment, since, in some scenarios, outcomes ranging from a lack of efficacy to deleterious responses may outweigh any expected performance enhancement.

\section{References}

Astorino, T.A., \& Roberson, D.W. (2010). Efficacy of acute caffeine ingestion for short-term high-intensity exercise performance: A systematic review. Journal of Strength \& Conditioning Research, 24(1), 257-265. PubMed doi:10.1519/JSC.0b013e3181c1f88a

Baguet, A., Bourgois, J., Vanhee, L., Achten, E., \& Derave, W. (2010). Important role of muscle carnosine in rowing performance. Journal of Applied Physiology (1985), 109(4), 1096-1101. doi:10.1152/jappl physiol.00141.2010

Bailey, S.J., Fulford, J., Vanhatalo, A., Winyard, P.G., Blackwell, J.R., DiMenna, F.J., . . Jones, A.M. (2010). Dietary nitrate supplementation enhances muscle contractile efficiency during knee-extensor exercise in humans. Journal of Applied Physiology (1985), 109(1), 135-148. doi:10.1152/japplphysiol.00046.2010

Bailey, S.J., Varnham, R.L., DiMenna, F.J., Breese, B.C., Wylie, L.J., \& Jones, A.M. (2015). Inorganic nitrate supplementation improves muscle oxygenation, $\mathrm{O}(2)$ uptake kinetics, and exercise tolerance at high but not low pedal rates. Journal of Applied Physiology (1985), 118(11), 1396-1405. doi:10.1152/japplphysiol.01141.2014

Bailey, S.J., Winyard, P., Vanhatalo, A., Blackwell, J.R., Dimenna, F.J., Wilkerson, D.P., ... Jones, A.M. (2009). Dietary nitrate supplementation reduces the $\mathrm{O}_{2}$ cost of low-intensity exercise and enhances tolerance to high-intensity exercise in humans. Journal of Applied Physiology (1985), 107(4), 1144-1155. doi:10.1152/japplphysiol. 00722.2009

Barnett, C., Costill, D.L., Vukovich, M.D., Cole, K.J., Goodpaster, B.H., Trappe, S.W., \& Fink, W.J. (1994). Effect of L-carnitine supplementation on muscle and blood carnitine content and lactate accumulation during high-intensity sprint cycling. International Journal of Sport Nutrition, 4(3), 280-288. PubMed doi:10.1123/ijsn.4.3.280

Baylis, A., Cameron-Smith, D., \& Burke, L.M. (2001). Inadvertent doping through supplement use by athletes: Assessment and management of the risk in Australia. International Journal of Sport Nutrition and 
Exercise Metabolism, 11(3), 365-383. PubMed doi:10.1123/ijsnem. 11.3.365

Bell, P.G., Walshe, I.H., Davison, G.W., Stevenson, E., \& Howatson, G. (2014). Montmorency cherries reduce the oxidative stress and inflammatory responses to repeated days high-intensity stochastic cycling. Nutrients, 6(12), 829-843. PubMed doi:10.3390/nu6020829

Bellar, D.M., Kamimori, G., Judge, L., Barkley, J.E., Ryan, E.J., Muller, M., \& Glickman, E.L. (2012). Effects of low-dose caffeine supplementation on early morning performance in the standing shot put throw. European Journal of Sport Science, 12(1), 57-61. doi:10. 1080/17461391.2010.536585

Bellinger, P.M. (2014). Beta-Alanine supplementation for athletic performance: An update. Journal of Strength \& Conditioning Research, 28(6), 1751-1770. PubMed doi:10.1519/JSC.0000000000000327

Benesch, R., \& Benesch, R.E. (1969). Intracellular organic phosphates as regulators of oxygen release by haemoglobin. Nature, 221(5181), 618-622. PubMed doi:10.1038/221618a0

Boorsma, R.K., Whitfield, J., \& Spriet, L.L. (2014). Beetroot juice supplementation does not improve performance of elite 1500-m runners. Medicine \& Science in Sports \& Exercise, 46(12), 2326-2334. PubMed doi:10.1249/MSS.0000000000000364

Braakhuis, A.J., Hopkins, W.G. (2015). Impact of dietary antioxidants on sport performance: A review. Sports Medicine, 45(7), 939-955. PubMed doi:10.1007/s40279-015-0323-x

Branch, J.D. (2003). Effect of creatine supplementation on body composition and performance: A meta-analysis. International Journal of Sport Nutrition and Exercise Metabolism, 13(2), 198-226. doi:10. 1123/ijsnem.13.2.198

Brewer, C.P., Dawson, B., Wallman, K.E., \& Guelfi, K.J. (2013). Effect of repeated sodium phosphate loading on cycling time-trial performance and VO2peak. International Journal of Sport Nutrition and Exercise Metabolism, 23(2), 187-194. PubMed doi:10.1123/ijsnem.23.2.187

Brewer, C.P., Dawson, B., Wallman, K.E., \& Guelfi, K.J. (2014). Effect of sodium phosphate supplementation on cycling time trial performance and VO2 1 and 8 days post loading. Journal of Sports Science \& Medicine, 13(3), 529-534. PubMed

Bruce, C.R., Anderson, M.E., Fraser, S.F., Stepto, N.K., Klein, R., Hopkins, W.G., \& Hawley, J.A. (2000). Enhancement of 2000-m rowing performance after caffeine ingestion. Medicine \& Science in Sports \& Exercise, 32(11), 1958-1963. doi:10.1097/00005768200011000-00021

Buck, C.L., Wallman, K.E., Dawson, B., \& Guelfi, K.J. (2013). Sodium phosphate as an ergogenic aid. Sports Medicine, 43(6), 425-435. PubMed doi:10.1007/s40279-013-0042-0

Buford, T.W., Kreider, R.B., Stout, J.R., Greenwood, M., Campbell, B., Spano, M., ... Antonio, J. (2007). International Society of Sports Nutrition position stand: Creatine supplementation and exercise. Journal of the International Society of Sports Nutrition, 4, 6. PubMed doi:10.1186/1550-2783-4-6

Burke, L.M. (2008). Caffeine and sports performance. Applied Physiology Nutrition and Metabolism, 33(6), 1319-1334. doi:10.1139/H08-130

Burke, L.M. (2013). Practical considerations for bicarbonate loading and sports performance. Nestlé Nutrition Institute Workshop Series, 75, 15-26. PubMed

Cade, R., Conte, M., Zauner, C., Mars, D., Peterson, J., Lunne, D., ... Packer, D. (1984). Effects of phosphate loading on 2, 3-diphosphoglycerate and maximal oxygen uptake. Medicine \& Science in Sports Exercise, 16(3), 263-268.

Carr, A.J., Hopkins, W.G., \& Gore, C.J. (2011). Effects of acute alkalosis and acidosis on performance: A meta-analysis. Sports Medicine, 41(10), 801-814. PubMed doi:10.2165/11591440-00000000000000
Carr, A.J., Slater, G.J., Gore, C.J., Dawson, B., \& Burke, L.M. (2011). Effect of sodium bicarbonate on $\left[\mathrm{HCO}_{3}{ }^{-}\right], \mathrm{pH}$, and gastrointestinal symptoms. International Journal of Sport Nutrition and Exercise Metabolism, 21(3), 189-194. PubMed doi:10.1123/ijsnem.21. 3.189

Chung, W., Shaw, G., Anderson, M.E., Pyne, D.B., Saunders, P.U., Bishop, D.J., \& Burke, L.M. (2012). Effect of 10 week beta-alanine supplementation on competition and training performance in elite swimmers. Nutrients, 4(12), 1441-1453. doi:10.3390/nu4101441

Cook, M.D., Myers, S.D., Blacker, S.D., \& Willems, M.E. (2015). New Zealand blackcurrant extract improves cycling performance and fat oxidation in cyclists. European Journal of Applied Physiology, 115(11), 2357-2365. PubMed doi:10.1007/s00421-015-3215-8

Cooper, R., Naclerio, F., Allgrove, J., \& Jimenez, A. (2012). Creatine supplementation with specific view to exercise/sports performance: An update. Journal of the International Society of Sports Nutrition, 9(1), 33. PubMed doi:10.1186/1550-2783-9-33

Deminice, R., Rosa, F.T., Franco, G.S., Jordao, A.A., \& de Freitas, E.C. (2013). Effects of creatine supplementation on oxidative stress and inflammatory markers after repeated-sprint exercise in humans. Nutrition, 29(9), 1127-1132. doi:10.1016/j.nut.2013.03.003

Duncan, C., Dougall, H., Johnston, P., Green, S., Brogan, R., Leifert, C., ... Benjamin, N. (1995). Chemical generation of nitric oxide in the mouth from the enterosalivary circulation of dietary nitrate. Nature Medicine, 1(6), 546-551. PubMed doi:10.1038/nm0695-546

Duncan, M.J., Stanley, M., Parkhouse, N., Cook, K., \& Smith, M. (2013). Acute caffeine ingestion enhances strength performance and reduces perceived exertion and muscle pain perception during resistance exercise. European Journal of Sport Science, 13(4), 392-399. doi:10.1080/17461391.2011.635811

Duncan, M.J., Thake, C.D., \& Downs, P.J. (2014). Effect of caffeine ingestion on torque and muscle activity during resistance exercise in men. Muscle \& Nerve, 50(4), 523-527. PubMed doi:10.1002/mus. 24179

Folland, J.P., Stern, R., \& Brickley, G. (2008). Sodium phosphate loading improves laboratory cycling time-trial performance in trained cyclists. Journal of Science \& Medicine in Sport, 11(5), 464-468. doi:10.1016/j.jsams.2007.04.004

French, C., McNaughton, L., Davies, P., \& Tristram, S. (1991). Caffeine ingestion during exercise to exhaustion in elite distance runners. Revision. Journal of Sports Medicine and Physical Fitness, 31(3), 425-432.

Ganio, M.S., Klau, J.F., Casa, D.J., Armstrong, L.E., \& Maresh, C.M. (2009). Effect of caffeine on sport-specific endurance performance: A systematic review. Journal of Strength \& Conditioning Research, 23(1), 315-324. PubMed doi:10.1519/JSC.0b013e31818b979a

Goldstein, E.R., Ziegenfuss, T., Kalman, D., Kreider, R., Campbell, B., Wilborn, C., ... Antonio, J. (2010). International society of sports nutrition position stand: Caffeine and performance. Journal of the International Society of Sports Nutrition, 7(1), 5. doi:10.1186/15502783-7-5

Gomez-Cabrera, M.C., Domenech, E., Romagnoli, M., Arduini, A., Borras, C., Pallardo, F.V., ... Viña, J. (2008). Oral administration of vitamin $\mathrm{C}$ decreases muscle mitochondrial biogenesis and hampers training-induced adaptations in endurance performance. American Journal of Clinical Nutrition, 87(1), 142-149. PubMed

Gonçalves, L.S., Painelli, V.S., Yamaguchi, G., de Oliveira, L.F., Saunders, B., da Silva, R.P., ... Gualano, B. (2017). Dispelling the myth that habitual caffeine consumption influences the performance response to acute caffeine supplementation. Journal of Applied Physiology, 123(1), 213-220. doi:10.1152/japplphysiol. 00260.2017 
Goss, F., Robertson, R., Riechman, S., Zoeller, R., Dabayebeh, I.D., Moyna, N., ... Metz, K. (2001). Effect of potassium phosphate supplementation on perceptual and physiological responses to maximal graded exercise. International Journal of Sport Nutrition and Exercise Metabolism, 11(1), 53-62. PubMed doi:10.1123/ijsnem. 11.1.53

Greenhaff, P.L., Casey, A., Short, A.H., Harris, R., Soderlund, K., \& Hultman, E. (1993). Influence of oral creatine supplementation of muscle torque during repeated bouts of maximal voluntary exercise in man. Clinical Science, 84(5), 565-571. PubMed doi:10.1042/ cs0840565

Greig, C., Finch, K.M., Jones, D.A., Cooper, M., Sargeant, A.J., \& Forte, C.A. (1987). The effect of oral supplementation with L-carnitine on maximum and submaximum exercise capacity. European Journal of Applied Physiology and Occupational Physiology, 56(4), 457-460. PubMed doi:10.1007/BF00417775

Harris, R.C., Soderlund, K., \& Hultman, E. (1992). Elevation of creatine in resting and exercised muscle of normal subjects by creatine supplementation. Clinical Science, 83(3), 367-374. PubMed doi:10.1042/ cs0830367

Hobson, R.M., Saunders, B., Ball, G., Harris, R.C., \& Sale, C. (2012). Effects of beta-alanine supplementation on exercise performance: A meta-analysis. Amino Acids, 43(1), 25-37. doi:10.1007/s00726-011$1200-\mathrm{Z}$

Hoon, M.W., Jones, A.M., Johnson, N.A., Blackwell, J.R., Broad, E.M., Lundy, B., ... Burke, L.M. (2014). The effect of variable doses of inorganic nitrate-rich beetroot juice on simulated 2, 000-m rowing performance in trained athletes. International Journal of Sports Physiology \& Performance, 9(4), 615-620. PubMed doi:10.1123/ ijspp.2013-0207

Howatson, G., McHugh, M.P., Hill, J.A., Brouner, J., Jewell, A.P., Van Someren, K.A., ... Howatson, S.A. (2010). Influence of tart cherry juice on indices of recovery following marathon running. Scandinavian Journal of Medicine \& Science in Sports, 20(6), 843-852. doi:10.1111/j.1600-0838.2009.01005.x

Hultman, E., Soderlund, K., Timmons, J.A., Cederblad, G., \& Greenhaff, P.L. (1996). Muscle creatine loading in men. Journal of Applied Physiology (1985), 81(1), 232-237. doi:10.1152/jappl.1996.81. 1.232

Jones, A.M. (2014). Dietary nitrate supplementation and exercise performance. Sports Medicine, 44(Suppl. 1), 35-45. doi:10.1007/s40279014-0149-y

Katz, A., Costill, D.L., King, D.S., Hargreaves, M., \& Fink, W.J. (1984). Maximal exercise tolerance after induced alkalosis. International Journal of Sports Medicine, 5(2), 107-110. doi:10.1055/s-20081025890

Kopec, B.J., Dawson, B.T., Buck, C., \& Wallman, K.E. (2016). Effects of sodium phosphate and caffeine ingestion on repeated-sprint ability in male athletes. Journal of Science \& Medicine in Sport, 19(3), 272-276. doi:10.1016/j.jsams.2015.04.001

Kraemer, W.J., Gordon, S.E., Lynch, J.M., Pop, M.E., \& Clark, K.L. (1995). Effects of multibuffer supplementation on acid-base balance and 2,3-diphosphoglycerate following repetitive anaerobic exercise. International Journal of Sports Nutrition, 5(4), 300-314. doi:10. 1123/ijsn.5.4.300

Kreider, R.B. (1999). Phosphorous in exercise and sport. In J.A. Driskell \& I. Wolinsky (Eds.), Macroelements, water and electrolytes in sport nutrition (pp. 29-43). Boca Raton, FL: CRC Press.

Kreider, R.B., Kalman, D.S., Antonio, J., Ziegenfuss, T.N., Wildman, R., Collins, R., ... Lopez, H.L. (2017). International Society of Sports Nutrition position stand: safety and efficacy of creatine supplementation in exercise, sport, and medicine. Journal of the
International Society of Sports Nutrition, 14, 18. PubMed doi:10. 1186/s12970-017-0173-Z

Kreider, R.B., Miller, G.W., Schenck, D., Cortes, C.W., Miriel, V., Somma, C.T., ... Hill, D. (1992). Effects of phosphate loading on metabolic and myocardial responses to maximal and endurance exercise. International Journal of Sports Nutrition, 2(1), 20-47. doi:10.1123/ijsn.2.1.20

Kreider, R.B., Miller, G.W., Williams, M.H., Somma, C.T., \& Nasser, T.A. (1990). Effects of phosphate loading on oxygen uptake, ventilatory anaerobic threshold, and run performance. Medicine \& Science in Sports \& Exercise, 22(2), 250-256. PubMed

Krustrup, P., Ermidis, G., \& Mohr, M. (2015). Sodium bicarbonate intake improves high-intensity intermittent exercise performance in trained young men. Journal of the International Society of Sports Nutrition, 12, 25. PubMed doi:10.1186/s12970-015-0087-6

Lancha Junior, A.H., de Painelli, V.S., Saunders, B., \& Artioli, G.G. (2015). Nutritional strategies to modulate intracellular and extracellular buffering capacity during high-intensity exercise. Sports Medicine, 45(Suppl. 1), 71-81. doi:10.1007/s40279-015-0397-5

Lanhers, C., Pereira, B., Naughton, G., Trousselard, M., Lesage, F.X., \& Dutheil, F. (2017). Creatine supplementation and upper limb strength performance: A systematic review and meta-analysis. Sports Medicine, 47(1), 163-173. doi:10.1007/s40279-0160571-4

Mainwood, G.W., \& Worsley-Brown, P. (1975). The effects of extracellular $\mathrm{pH}$ and buffer concentration on the efflux of lactate from frog sartorius muscle. Journal of Physiology, 250(1), 1-22. PubMed doi:10.1113/jphysiol.1975.sp011040

Marconi, C., Sassi, G., Carpinelli, A., \& Cerretelli, P. (1985). Effects of L-carnitine loading on the aerobic and anaerobic performance of endurance athletes. European Journal of Applied Physiology and Occupational Physiology, 54(2), 131-135. PubMed doi:10.1007/ BF02335919

McMahon, N.F., Leveritt, M.D., \& Pavey, T.G. (2016). The effect of dietary nitrate supplementation on endurance exercise performance in healthy adults: A systematic review and meta-analysis. Sports Medicine, 47(4), 735-756. doi:10.1007/s40279-016-0617-7

McNaughton, L., \& Cedaro, R. (1992). Sodium citrate ingestion and its effects on maximal anaerobic exercise of different durations. European Journal of Applied Physiology and Occupational Physiology, 64(1), 36-41. PubMed

McNaughton, L.R. (1990). Sodium citrate and anaerobic performance: Implications of dosage. European Journal of Applied Physiology and Occupational Physiology, 61(5-6), 392-397. doi:10.1007/ BF00236058

Muggeridge, D.J., Sculthorpe, N., James, P.E., \& Easton, C. (2017). The effects of dietary nitrate supplementation on the adaptations to sprint interval training in previously untrained males. Journal of Science \& Medicine in Sport, 20(1), 92-97. doi:10.1016/j.jsams. 2016.04.014

Nassis, G.P., Sporer, B., \& Stathis, C.G. (2016). Beta-Alanine efficacy for sports performance improvement: from science to practice. British Journal of Sports Medicine, 51(8), 626-627. PubMed doi:10.1136/ bjsports-2016-097038

Novakova, K., Kummer, O., Bouitbir, J., Stoffel, S.D., Hoerler-Koerner, U., Bodmer, M., ... Krahenbuhl, S. (2016). Effect of L-carnitine supplementation on the body carnitine pool, skeletal muscle energy metabolism and physical performance in male vegetarians. European Journal of Nutrition, 55(1), 207-217. PubMed doi:10.1007/s00394015-0838-9

Nyakayiru, J., Jonvik, K.L., Trommelen, J., Pinckaers, P.J., Senden, J.M., van Loon, L.J., \& Verdijk, L.B. (2017). Beetroot juice 
supplementation improves high-intensity intermittent type exercise performance in trained soccer players. Nutrients, 9(3), 314. doi:10. 3390/nu9030314

Paton, C., Costa, V., \& Guglielmo, L. (2015). Effects of caffeine chewing gum on race performance and physiology in male and female cyclists. Journal of Sports Sciences, 33(10), 1076-1083. PubMed doi:10. 1080/02640414.2014.984752

Peeling, P. (2015). Phosphate. In L.M. Castell, S.J. Stear, \& L.M. Burke (Eds.), Nutritional supplements in sport, exercise and health: An A-Z guide (pp. 205-206). New York, NY: Routledge.

Peeling, P., Cox, G.R., Bullock, N., \& Burke, L.M. (2015). Beetroot juice improves on-water $500 \mathrm{~m}$ time-trial performance, and laboratorybased paddling economy in national and international-level kayak athletes. International Journal of Sport Nutrition and Exercise Metabolism, 25(3), 278-284. PubMed doi:10.1123/ijsnem.20140110

Perkins, I.C., Vine, S.A., Blacker, S.D., \& Willems, M.E. (2015). New Zealand blackcurrant extract improves high-intensity intermittent running. International Journal of Sport Nutrition and Exercise Metabolism, 25(5), 487-493. doi:10.1123/ijsnem.2015-0020

Rawson, E.S., \& Persky, A.M. (2007). Mechanisms of muscular adaptations to creatine supplementation: Review article. International SportMed Journal, 8(2), 43-53.

Requena, B., Zabala, M., Padial, P., \& Feriche, B. (2005). Sodium bicarbonate and sodium citrate: ergogenic aids? Journal of Strength \& Conditioning Research, 19(1), 213-224. PubMed

Reynolds, C., Halpenny, C., Hughes, C., Jordan, S., Quinn, A., \& Egan, B. (2016). Acute ingestion of beetroot juice does not improve repeated sprint performance in male team sport athletes. Proceedings of the Nutrition Society, 75(OCE3), E97. doi:10.1017/S0029665116 001129

Saunders, B., Elliott-Sale, K., Artioli, G.G., Swinton, P.A., Dolan, E., Roschel, H., ... Gualano, B. (2016). Beta-Alanine supplementation to improve exercise capacity and performance: A systematic review and meta-analysis. British Journal of Sports Medicine, 51(8), 658-669. PubMed doi:10.1136/bjsports-2016-096396

Schilling, B.K., Stone, M.H., Utter, A., Kearney, J.T., Johnson, M., Coglianese, R., ... Stone, M.E. (2001). Creatine supplementation and health variables: A retrospective study. Medicine \& Science in Sports \& Exercise, 33(2), 183-188. PubMed doi:10.1097/00005768200102000-00002

Schneiker, K.T., Bishop, D., Dawson, B., \& Hackett, L.P. (2006). Effects of caffeine on prolonged intermittent-sprint ability in team-sport athletes. Medicine \& Science in Sports \& Exercise, 38(3), 578-585. doi:10.1249/01.mss.0000188449.18968.62

Siegler, J.C., Marshall, P.W.M., Bishop, D., Shaw, G., \& Green, S. (2016). Mechanistic insights into the efficacy of sodium bicarbonate supplementation to improve athletic performance. Sports Medicine - Open, 2(1), 41. PubMed doi:10.1186/s40798-016-0065-9

Siegler, J.C., Marshall, P.W.M., Bray, J., \& Towlson, C. (2012). Sodium bicarbonate supplementation and ingestion timing: Does it matter? Journal of Strength \& Conditioning Research, 26 (7), 1953-1958. PubMed doi:10.1519/JSC.0b013e3182392960

Somerville, V., Bringans, C., \& Braakhuis, A. (2017). Polyphenols and performance: A systematic review and meta-analysis. Sports Medicine, 47(8), 1589-1599. PubMed doi:10.1007/s40279-0170675-5

Spriet, L.L. (2014). Exercise and sport performance with low doses of caffeine. Sports Medicine, 44(Suppl. 2), 175-184. doi:10.1007/ s40279-014-0257-8

Steenge, G.R., Simpson, E.J., \& Greenhaff, P.L. (2000). Protein- and carbohydrate-induced augmentation of whole body creatine retention in humans. Journal of Applied Physiology (1985), 89(3), 1165-1171. doi:10.1152/jappl.2000.89.3.1165

Stellingwerff, T., Decombaz, J., Harris, R.C., \& Boesch, C. (2012). Optimizing human in vivo dosing and delivery of $\beta$-alanine supplements for muscle carnosine synthesis. Amino Acids, 43(1), 57-65. doi:10.1007/s00726-012-1245-7

Stephens, F.B., Constantin-Teodosiu, D., \& Greenhaff, P.L. (2007). New insights concerning the role of carnitine in the regulation of fuel metabolism in skeletal muscle. Journal of Physiology, 581(2), 431-444. doi:10.1113/jphysiol.2006.125799

Stephens, F.B., Evans, C.E., Constantin-Teodosiu, D., \& Greenhaff, P.L. (2007). Carbohydrate ingestion augments L-carnitine retention in humans. Journal of Applied Physiology (1985), 102(3), 1065-1070. doi:10.1152/japplphysiol.01011.2006

Talanian, J.L., \& Spriet, L.L. (2016). Low and moderate doses of caffeine late in exercise improve performance in trained cyclists. Applied Physiology Nutrition \& Metabolism, 41(8), 850-855. doi:10.1139/ apnm-2016-0053

Thompson, C., Vanhatalo, A., Jell, H., Fulford, J., Carter, J., Nyman, L., ... Jones, A.M. (2016). Dietary nitrate supplementation improves sprint and high-intensity intermittent running performance. Nitric Oxide, 61, 55-61. PubMed doi:10.1016/j.niox.2016. 10.006

Thompson, C., Wylie, L.J., Fulford, J., Kelly, J., Black, M.I., McDonagh, S.T., . . Jones, A.M. (2015). Dietary nitrate improves sprint performance and cognitive function during prolonged intermittent exercise. European Journal of Applied Physiology, 115(9), 1825-1834. PubMed doi:10.1007/s00421-015-3166-0

Tomcik, K.A., Camera, D.M., Bone, J.L., Ross, M.L., Jeacocke, N.A., Tachtsis, B., ... Burke, L.M. (2018). Effects of creatine and carbohydrate loading on cycling time trial performance. Medicine \& Science in Sports \& Exercise, 50(1), 141-150. doi:10.1249/MSS. 0000000000001401

Tsao, R. (2010). Chemistry and biochemistry of dietary polyphenols. Nutrients, 2(12), 1231-1246. PubMed doi:10.3390/nu2121231

Urwin, C.S., Dwyer, D.B., \& Carr, A.J. (2016). Induced alkalosis and gastrointestinal symptoms after sodium citrate ingestion: A doseresponse investigation. International Journal of Sport Nutrition and Exercise Metabolism, 26(6), 542-548. doi:10.1123/ijsnem.20150336

Vanhatalo, A., Bailey, S.J., Blackwell, J.R., DiMenna, F.J., Pavey, T.G., Wilkerson, D.P., ... Jones, A.M. (2010). Acute and chronic effects of dietary nitrate supplementation on blood pressure and the physiological responses to moderate-intensity and incremental exercise. American Journal of Physiology. Regulatory, Integrative and Comparative Physiology, 299(4), R1121-R1131. PubMed doi:10.1152/ ajpregu.00206.2010

Volek, J.S., \& Rawson, E.S. (2004). Scientific basis and practical aspects of creatine supplementation for athletes. Nutrition, 20(7-8), 609-614. PubMed doi:10.1016/j.nut.2004.04.014

Wall, B.T., Stephens, F.B., Constantin-Teodosiu, D., Marimuthu, K., Macdonald, I.A., \& Greenhaff, P.L. (2011). Chronic oral ingestion of L-carnitine and carbohydrate increases muscle carnitine content and alters muscle fuel metabolism during exercise in humans. Journal of Physiology, 589(4), 963-973. PubMed doi:10.1113/jphysiol.2010. 201343

Wellington, B.M., Leveritt, M.D., \& Kelly, V.G. (2017). The effect of caffeine on repeat high intensity effort performance in rugby league players. International Journal of Sports Physiology \& Performance, 12(2), 206-210. doi:10.1123/ijspp.2015-0689

West, J.S., Ayton, T., Wallman, K.E., \& Guelfi, K.J. (2012). The effect of 6 days of sodium phosphate supplementation on appetite, energy 
intake, and aerobic capacity in trained men and women. International Journal of Sport Nutrition and Exercise Metabolism, 22(6), 422-429. doi:10.1123/ijsnem.22.6.422

Wiles, J.D., Coleman, D., Tegerdine, M., \& Swaine, I.L. (2006). The effects of caffeine ingestion on performance time, speed and power during a laboratory-based $1 \mathrm{~km}$ cycling time-trial. Journal of Sports
Sciences, 24(11), 1165-1171. PubMed doi:10.1080/02640410500 457687

Wylie, L.J., Bailey, S.J., Kelly, J., Blackwell, J.R., Vanhatalo, A., \& Jones, A.M. (2016). Influence of beetroot juice supplementation on intermittent exercise performance. European Journal of Applied Physiology, 116(2), 415-425. doi:10.1007/s00421-015-3296-4 